\title{
Casualty analysis of Aframax tankers
}

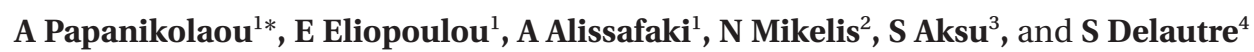

${ }^{1}$ Ship Design Laboratory, National Technical University of Athens, Athens, Greece

${ }^{2}$ Mikelis Consulting (currently IMO), UK

${ }^{3}$ Universities of Glasgow and Strathclyde, UK

${ }^{4}$ Direction des Construction Navales (formerly Bureau Veritas), France

The manuscript was received on 15 September 2006 and was accepted after revision for publication on 14 November 2006.

DOI: 10.1243/14750902JEME74

\begin{abstract}
The paper presents detailed results of a comprehensive analysis pertaining to Aframax tanker incidents and accidents that occurred in the last 26 years. The thorough review of the captured accident database information and the analysis of the historical records provided essential qualitative and quantitative information on a variety of parameters relevant to risk-based methodologies, namely the degree of severity and frequencies of accidents broken down into the pre-1990 and post-1990 periods, the spilled tonne rates and the impact of hull design and of ship's age, particularly on non-accidental structural failure accidents and geography of worldwide oil spills. The generated information enables conclusions on Aframax tanker accidents and of tankers in general to be drawn, for further exploitation in risk based design, operation and regulations.
\end{abstract}

Keywords: frequency of accidents, fault trees, event trees, risk analysis, tanker hull design

\section{INTRODUCTION}

A rational database of Aframax tankers was set up in the framework of the EU-funded project entitled 'pollution, prevention and control' (POP\&C) to enable the full exploitation of the raw incident data compiled and which was commercially available by Lloyd's Maritime Information Service (LMIS). The textual information presented in the incident data were reanalysed by a team of the POP\&C project partners and were introduced in the newly developed database to produce appropriate accident statistics.

The analysis was focused on six major accident categories, namely non-accidental structural failure, collision, contact, grounding, fire, and explosion. Whilst, on one hand, the analysis made an attempt to identify basic events leading to these major casualty categories, on the other hand, factors related to consequences such as the degree of severity of accidents, oil spill occurrence, and impact of hull design were also investigated.

* Corresponding author: Ship Design Laboratory, National Technical University of Athens, 9 Heroon Polytechniou, Zografou, Athens, 15 773, Greece.email: papa@deslab.ntua.gr

\section{METHODOLOGY OF WORK}

\subsection{Hazard identification and ranking}

The first step of a risk assessment methodology is to carry out a hazard identification and ranking (HAZID) study. In order to perform the HAZID study efficiently, the safety matter under consideration and scope of the study need to be clearly defined. The scope could be limited to a certain ship type, or size, specific accident scenarios, specific operational conditions, typical design and operation concepts, etc. In the context of the POP\&C project, the main purpose was the identification of main hazards that lead to a vessel's loss of watertight integrity (LOWI) and consequently cause pollution and environmental damage. Such a HAZID study can conveniently be carried out by analysing the incident and accident performance of a representative sector of the industry. Therefore, in order to demonstrate the methodology which is being developed, the POP\&C project selected to analyse the Aframax class of tankers. Reasons for this selection were the relatively large market segment of the Aframax tankers, past spectacular catastrophic tanker accidents involving Aframax tankers and relatively high number of single-hull 
Aframax tankers which are currently operational and expected to continue to operate until they reach the recently amended (accelerated) phase-out date [1].

Although the scope of the POP\&C project is limited to tanker vessels of Aframax size and to accident scenarios that will lead to vessel's LOWI, which consequently causes pollution and environmental damage, the risks are not limited to environmental risk, but risks to human life and property are also considered within the study.

Assessment of hazards can conveniently be made by gathering data in the following three steps:

\section{(a) basic information; \\ (b) hazard identification; \\ (c) ranking.}

Basic information will include the scope of the study, the objectives, and background information on the system to be analysed (system, function, and operation). In the hazard identification process, using several structured analysis methods, as many hazards as possible are identified. It makes use of the experience of the experts employed as well as of the accident and incident data collected prior to the study. Each hazard identified is coarsely analysed in terms of possible causes for its occurrence, its possible effects, and foreseen safeguards to prevent the hazard and/or possible scenarios developing from it, or to mitigate the effects and consequences. In the ranking process, each scenario is assessed regarding the likelihood or frequency of its occurrence and regarding the severity of its possible effects and consequences.

Several mainstream techniques (what-if analysis, what-if and checklist analysis, hazard and operability analysis, failure modes and effects analysis, fault tree analysis, event tree analysis, and human hazard identification) are used for HAZID in the maritime world. These methods were reviewed and a method utilizing fault tree and event tree techniques was selected to be used in the project.

Fault tree analysis provides a disciplined rigorous approach to the identification and quantification of system failures. The objective of a fault tree analysis is to identify the potential combination of events that can make a system fail to perform its function. Fault trees provide qualitative and quantitative information. In terms of qualitative information, even in case of missing data, a fault tree analysis can provide significant insights regarding the causes leading to the top event. By studying the logical interactions of the individual basic (root cause) events in a fault tree, the importance of each basic event in relation to its contribution to the occurrence of the top event can be estimated. Quantitative information can be obtained by evaluating the frequencies of the minimal cut sets, therefore obtaining the frequency of the top event. Relevant data may be extracted from databases on accidents and incidents or, if data are not available, expert judgement may be used.

An event tree graphically models the possible outcomes of an initiating event capable of producing an end event of interest (usually undesirable, such as an accident). It provides a systematic means of delineating accident sequences in terms of the event successes and failures that make up those sequences. Event tree analysis can provide qualitative descriptions of potential problems (combinations of events producing various types of problem from initiating events) and quantitative estimates of event frequencies or probabilities of each outcome which still provide useful information in demonstrating the relative importance of various failure sequences.

An event tree starts with one initiating event (in this case these are main accident categories of collision, grounding, contact, non-accidental structural failure, fire, and explosions) and terminates in multiple end states, considering all possible outcomes (such as total loss of ship due to loss of stability, ship breaks into pieces, and ship stays afloat with various degrees of damage) by taking into consideration both the success and the failure of foreseen safeguards and measures to prevent the development of subsequent events or to mitigate their magnitude. By estimating the probability that a specific safeguard and measure is successful or not, the probability of each of the possible outcomes from the initiating event can be calculated. However, even if not quantified, the event tree provides significant insights by providing information on the best possible locations where certain risk control options or pollution control options can be employed in order to prevent the escalation of sequence of events from becoming more critical (e.g. a small fire leading to a large-scale explosion or a fatigue cracking causing the ship to break into pieces because of loss of structural strength).

\subsection{Development of fault trees and event trees}

The main incident categories aligned with the objectives of the POP\&C were identified as collision, contact, grounding, non-accidental structural failure, fire, and explosion, and the POP\&C risk model was developed.

A fault tree and an event tree for each of the six main accident categories were developed by the POP\&C partners. The fault trees developed for 
the collision and grounding accident categories are shown in the ANNEX, Figs 12 and 13 respectively. Similarly, event trees developed for the collision and grounding accident categories are presented in the Appendix, Figs 14 and 15 respectively.

As stated previously, although unpopulated (without frequencies) POP\&C risk contribution fault trees and event trees of the identified six accident categories which can potentially lead to LOWI of a tanker's hull provide qualitative information that can still be useful, quantitative assessment can only be made if these are populated by a comprehensive analysis of past accidents data and/or use of expert judgement. For this reason, a rational database of Aframax tankers was set up to enable the full exploitation of the raw incident and accident data that were commercially available from LMIS. Much of the incident and accident information contained in the LMIS database is in textual format and it is consequently difficult to extract and analyse this information systematically. Therefore, the textual information presented in the LMIS database had to be reanalysed by a team of POP\&C project partners before it could be introduced into the newly developed database.

\subsection{Source of data}

The basic information was a comprehensive set of incident and accident records which was originally obtained mostly from LMIS and updated by INTERTANKO for later years, concerning all subtypes and sizes of tankers and covering the period from 1978 to early 2004.

The selection of the particular tanker ship size, namely Aframax, was based on dead weight tonnage (DWT) size segment 80 000-119 999. In addition to the size, the basic Aframax subtypes were also selected, namely oil tankers, crude tankers, shuttle tankers, product carriers, and tankers that can transport either chemicals or oil tankers. On the other hand, vessels that can transport, ore, bulk goods, or oil, and chemical tankers were excluded from the analysis since these tanker subtypes have special design features and layout, which are not representative of the whole Aframax class of tankers. Of all the available records, 1294 accident records were finally extracted to be further analysed with respect to size and particular tanker subtypes covering the period from 1978 to early 2004 [2].

The existing information of the initial records covered the following:

(a) ship's basic characteristics (Lloyd's RegisterInternational Maritime Organization (IMO), ship Name, ship type, built year and DWT); (b) type of incident or accident according to LMIS coding, namely 'hull and machinery', 'collision', 'grounding, 'fire or explosion' and 'miscellaneous';

(c) year and location (Marsden grid) of the occurrence of accidents;

(d) degree of severity of each incident or accident, according to LMIS coding;

(e) basic information concerning environmental pollution (quantity and units);

(f) Number of killed and missing persons and the case of Dead ship condition; also complementary texts with a raw description of the incident or accident concerning the causes, the ship's operating condition at the time of incident or accident, the location, environmental pollution, and the outcome concerning the resulting ship's condition.

\subsection{POP\&C database}

The initial selected records were imported into a database in order to enable a comprehensive analysis of the data to be made. The POP\&C Tanker Casualty Database has been set up in Microsoft access format and can run on any personal computer employing Microscoft Office 2000 (or later versions). The database was further developed in order to register the information of the complementary texts in a proper manner (using checklists, pull-down menus, etc.) so that the information could be easily retrieved and systematically analysed. The registered information was constructed such that the POP\&C risk contribution fault trees and event trees developed by the project could be populated partially or completely. Synoptically, the following considerations were included in the new version.

1. New major categories of incidents and accidents were predefined, namely non-accidental structural failure, collision, contact, grounding, fire, explosion, failure of hull fittings, machinery failure, and unknown reasons.

2. Each incident and accident category was further described by subcategories and/or descriptions of causes and exact ship's location. Basically, the following considerations were defined in order to follow the POP\&C risk contribution fault trees:

(a) non-accidental structural failure occurrence due to 'structural degradation', due to 'poor design or construction' or due to 'excessive loading';

(b) collision occurrence (ship to ship) because of 'failure to supervise route' or 'failure of avoidance manoeuvring'; 
(c) contact: 'contact with floating object' or 'contact with fixed installation';

(d) grounding: 'drift grounding' or 'powered grounding';

(e) fire as initiating event due to 'internal source', 'external source' (piracy or spread of fire from another ship) or due to 'atmospheric conditions' (lightning) together with further description on the ship's main location and ignition source;

(f) explosion as initiating event in the cargo or slop tanks, in the aft area, on deck or in the ballast tanks or void spaces, together with ignition source information.

3. Enhanced oil spill information concerning the location, proximity to shore, total oil spill quantity, and the amount recovered was recorded.

4. Information on fatalities and injuries, namely the numbers of serious injuries, non-serious injuries, fatalities and missing persons, was registered.

5. Event location and ship's operating condition were defined according to IMO relevant descriptions [3]. Basic information on the environmental condition at the time of the incident or accident was noted.

6. Outcome of the incident or accident with respect to the ship's condition after the event such as 'remains afloat', 'total loss', 'sailed by her means' or 'towed away', 'LOWI', 'minor repairs' or 'major repairs', 'sold for demolition', 'broken up', 'no damage reported or sustained' were documented.

7. finally, information regarding the ship's hull type [single hull (SH), double hull (DH), double bottom (DB), and double side (DS)] involved in the incident or accident was provided by Lloyd's Register and was input to the database.

\subsection{Population of POP\&C database}

The process of populating the POP\&C database was carried out by the present authors. Each partner organization undertook the task of studying the accompanying complementary textual information for each incident or accident record and entering the relevant information in the format specified above. Because of the fuzzy character of the majority of the available information of the records and also for ensuring the non-biased assessment of the incident records to the extent feasible, a second round review of all records was conducted, by exchanging the records between the analysts. It should be noted that, when the raw record data were poor, requiring the personal judgement of the analysts for proper population of the database, a slightly different degree of 'strictness' was observed in relation to the assumptions made.

\subsection{Critical review of casualty databases}

The POP\&C incident and accident categorisation represents significant deviations from the categorization adopted in the LMIS database [4], which to a large extent has become an industry standard over the years. For example, 'Fire and explosions' are treated as one category in LMIS and in other data sources. Upon examining the causes and consequences of fire and of explosion accidents, it was realized that these differ considerably and, because the scope of the analysis is to use this information on risk-based methodologies, it was considered essential to define accurately the first initiating event. Therefore, fire and explosion events were investigated separately.

The LMIS database has also a category called 'hull and machinery', which incorporates structural failures, failures of machinery and propulsion devices, and failures of hull and deck fittings, all of which should be rationally examined under separate categories as they are associated with different fault and event trees. In the POP\&C database, the corresponding 'hull and machinery' incidents and accidents were analysed under one accident category, namely non-accidental structural failure (potentially a LOWI occurrence; see below) and two incident categories, namely failure of hull fittings (a non-LOWI occurrence), and machinery failure (a non-LOWI occurrence).

In addition, contact accidents (collision between a tanker and a fixed installation or a floating object) were separated from collision accidents because they differ as an accident mechanism from ship-toship collisions. Furthermore, as implied earlier, each major accident category was subdivided by a unique sequence of subcategories and complemented by descriptions of causes and consequences, all of which follows the POP\&C risk contribution fault trees and event trees developed by the project.

For the purpose of the POP\&C analysis, accidents are classified according to the six LOWI categories. This categorization is carried out in accordance with the resulting event, such that, for example, failure of steering equipment resulting in grounding is classified as a grounding event. Furthermore, failure of steering equipment which does not lead to one of the six accident categories is assigned to an incident category outside the six LOWI categories, as also are cases of failures of hull and deck fittings which do not lead to LOWI (all these are also termed here as 'incidents').

Event location, oil spill location, and ship's operating conditions at the time of the incident or accident are properly described according to IMO 
formal relevant descriptions. Where available, detailed oil spill information, environmental condition at the time of incident or accident (sea state and/or wind force) and description of the outcome of the incident or accident with respect to the vessel's condition, such as no sustained damage, sustained damage requiring minor or major repairs, and total loss, are also recorded in the database.

\section{REVIEW OF RESULTS}

\subsection{Degree of severity}

The consequences of accidents were analysed in relation to the degree of severity levels: 'total loss', 'serious', and 'non-serious' as defined in the LMIS database. The results for each accident category as a percentage as well as frequency are given in Figs 1(a) and (b).

The percentage of serious and catastrophic consequences (serious and total losses) are almost similar, concerning the navigational accidents (collisions, contacts, and groundings) and the non-accidental structural failures.

Explosion accidents present very high percentage of severe consequences (32 per cent serious and 22 per cent total losses) and, if it happens, the particular accident category is characterized as the most severe event in terms of consequences, with fire accidents to be the second most severe events.

Interestingly, explosion is the least frequent accident category, while fire is the second least frequent. Furthermore, the frequency of explosion accidents

AFRAMAX Tankers, Degree of severity Studied period 1978-2003

EColizion a Contact a arounding a Fre DExplosion DNA6F

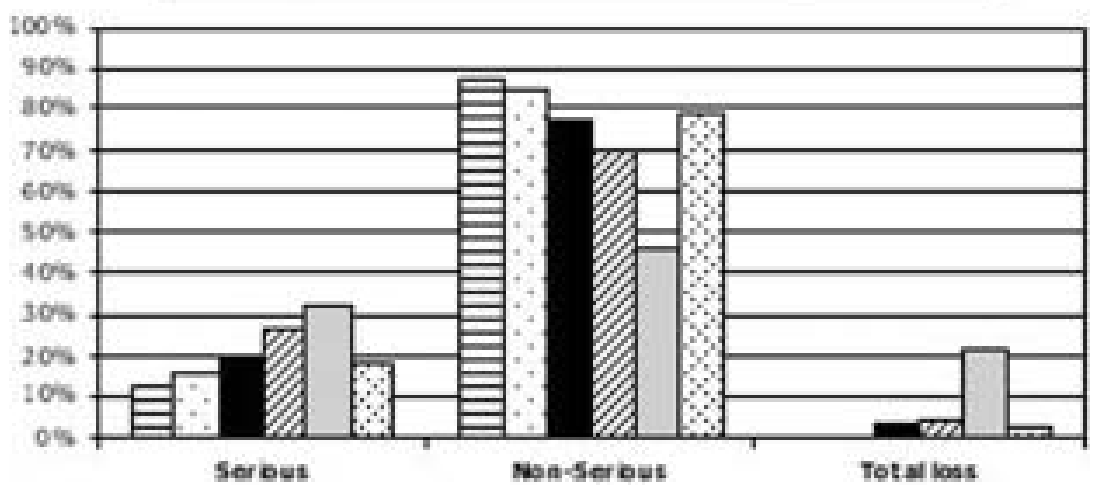

(a)

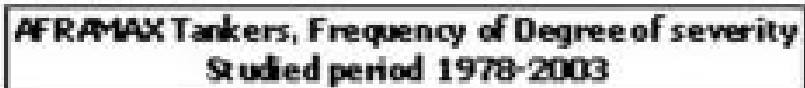

GCokion $\square$ Contact a Gounding ש Fire DExplosion aNAGF

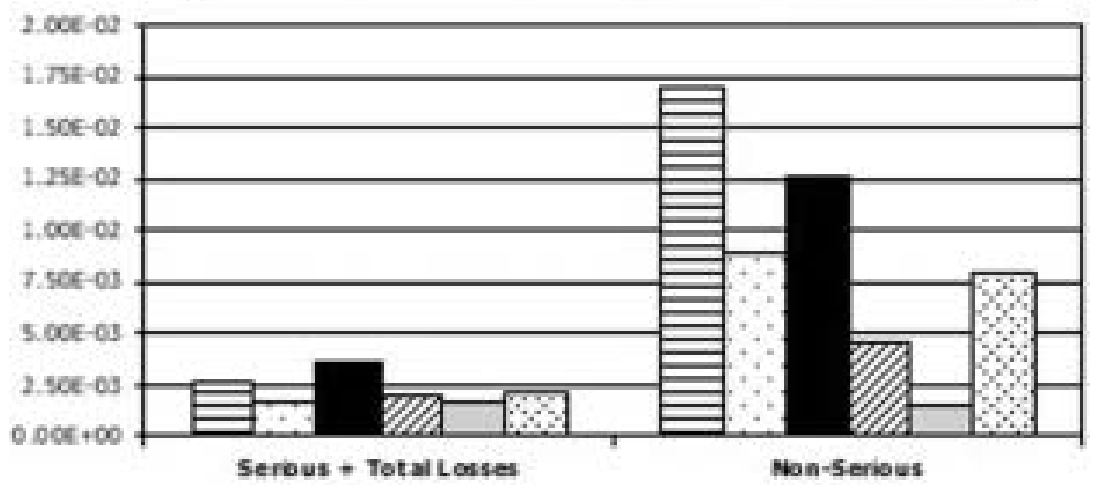

(b)

Fig. 1 (a) Degree of severity of accidents; (b) frequency of degree of severity 
with severe consequences (see serious degree and total losses) varies at the same levels as with the other accident categories [Fig. 1(b)]. Grounding accidents present the highest frequency of accidents with severe consequences.

\subsection{Frequencies of accidents}

In Fig. 2, the overall accident rate per ship year of all the six accident categories is presented, as well as the rate per accident category.

It is evident that the frequency of occurrence of Aframax accidents has been greatly reduced in recent years. A series of IMO regulations concerning the prevention of incidents and accidents have apparently contributed to these improvements. A separate study was conducted [5] concerning the influence of regulations on the safety record of Aframax tankers. According to the study, a number of key regulations appear to have contributed to the declining trends of accident rates.

It is worthwhile to state that the reduction in the frequency of accidents has not been accompanied by an equivalent reduction in their environmental pollution consequences [6], as indicated in Fig. 3.

\subsection{Spilled tonne rates}

Spilled tonne rates are defined as the rate of the quantity of oil spilled to the corresponding fleet at risk. In Fig. 4, the annual spilled tonne rate of the six studied accident categories are presented. The rate is slightly increased in the post-1990 period, as indicated by the corresponding average values (horizontal lines in the figure), meaning that the environmental pollution per ship year is increased as well. According to the historical data, this increase is due to the navigational accidents (Fig. 5) and to non-accidental structural failures (Fig. 6). Fire accidents have almost negligible spilled tonne rates throughout the studied period, whereas explosions produced almost zero values in the post-1990 period.

\subsection{Impact of hull design}

An extensive study about the tankers' hull type and resulted oil spills has been presented in reference [7]. An interesting example of a comparison between tanker hull configurations is the comparison of the performance of the pre-MARPOL single-hull tankers with no segregated ballast tanks protectively located (SH-non-SBT/PL tankers) to the performance of the post-MARPOL single-hull tankers with segregated ballast tanks protectively located (SH-SBT/PL tankers). (MARPOL is the International Convention for the

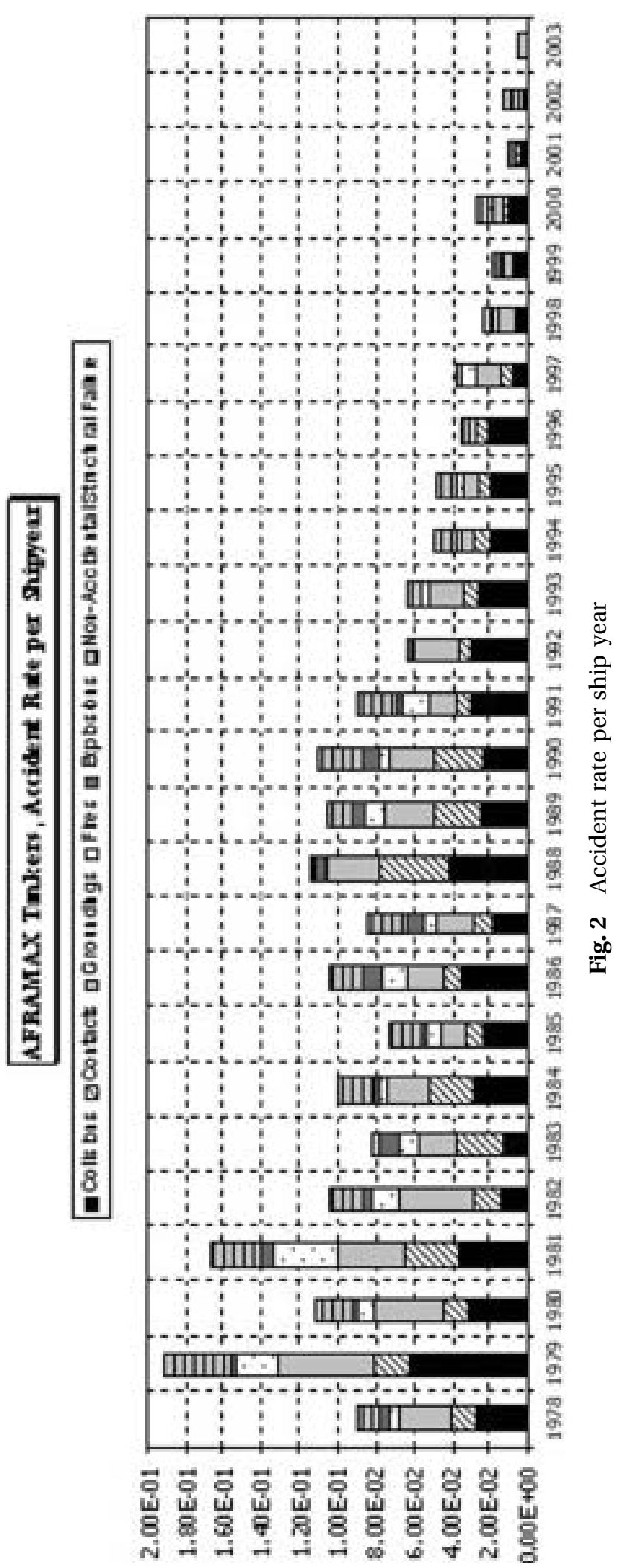




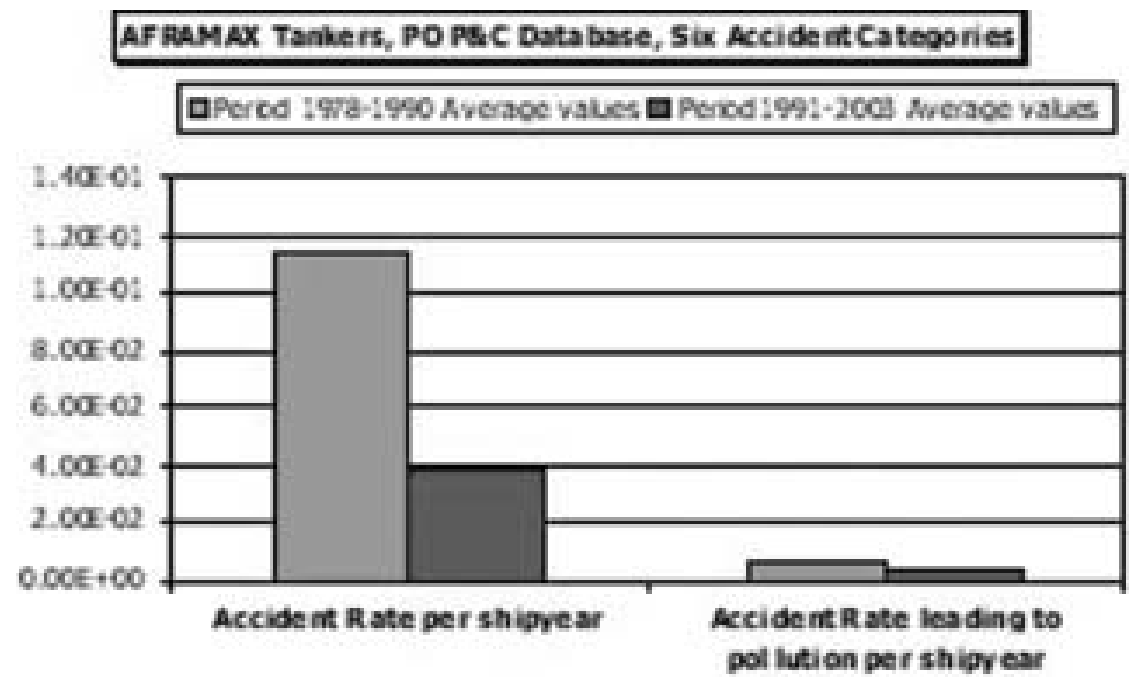

Fig. 3 Rates of accidents in pre-1990 and post-1990 periods

Prevention of Marine Pollution from Ships.) It was found that the performance of the SH-SBT/PL tankers is seen to be far superior to those of the SH-non-SBT/PL tanker (Table 1).
Interestingly, when the data for the 26 year period of the analysis is split into two (1978-1990 and 1991-2003) the superiority of the SH-SBT/PL tankers over the SH-non-SBT/PL tankers dramatically

Table 1 Aframax accidents (non-accidental structural failure, collision, contact, grounding, fire and explosion): oil pollution rates by full type for the period of 1978-2003 (SH-non-SBT/PL tankers, pre-MARPOL single-hull tankers with no segregated ballast tanks protectively located; SH-SHT/PL tankers, post-MARPOL singlehull tankers with segregated ballast tanks protectively located; DB tankers, double-bottom tankers; DS tankers, double-side tankers; DH tankers, double-hull tankers)

\begin{tabular}{|c|c|c|c|c|c|c|}
\hline & All ships & $\begin{array}{l}\text { SH-non-SBT/PL } \\
\text { tanker }\end{array}$ & $\begin{array}{l}\text { SH-SBT/PL } \\
\text { tanker }\end{array}$ & DB tanker & DS tanker & DH tanker \\
\hline & \multicolumn{6}{|c|}{ Period 1978-2003 } \\
\hline Number of ship years & 11652 & 6246 & 1770 & 372 & 1093 & 2171 \\
\hline Number of accidents with no spill & 739 & 536 & 58 & 40 & 45 & 50 \\
\hline Number of accidents with $0-7 \mathrm{t}$ spill & 20 & 14 & 4 & 1 & 0 & 1 \\
\hline Number of accidents with $7-700 \mathrm{t}$ spill & 20 & 12 & 4 & 0 & 1 & 3 \\
\hline Total number of accidents & 789 & 578 & 67 & 43 & 47 & 54 \\
\hline Quantity spilled in $0-7 \mathrm{t}$ spills & 27 & 19.6 & 7 & 0 & 0 & 1 \\
\hline Quantity spilled in $7-700 \mathrm{t}$ spills & 4874 & 3559 & 673 & 0 & 280 & 362 \\
\hline Quantity spilled in $700+\mathrm{t}$ spills & 361393 & 347608 & 837 & 4377 & 8571 & 0 \\
\hline Total quantity spilled & 366294 & 351186 & 1517 & 4377 & 8851 & 363 \\
\hline \multirow[t]{2}{*}{ Index (t/ship years) } & 31.4 & 56.2 & 0.9 & 11.8 & 8.1 & 0.2 \\
\hline & \multicolumn{6}{|c|}{ Period 1978-1990 } \\
\hline Number of years & 13 & 13 & 13 & 13 & 11 & 6 \\
\hline Number of accidents with no spill & 525 & 445 & 36 & 25 & 18 & 1 \\
\hline Number of accidents with spill & 32 & 28 & 2 & 2 & 0 & 0 \\
\hline Total number of accidents & 557 & 473 & 38 & 27 & 18 & 1 \\
\hline Total quantity & 135095 & 129341 & 1377 & 4377 & 0 & 0 \\
\hline \multirow[t]{2}{*}{ Index (t/ship years) } & 26.8 & 31.4 & 2.8 & 30.0 & 0.0 & 0.0 \\
\hline & \multicolumn{6}{|c|}{ Period 1991-2003 } \\
\hline Number of years & 13 & 13 & 13 & 13 & 13 & 13 \\
\hline Number of ship years & 6611 & 2127 & 1286 & 226 & 850 & 2122 \\
\hline Number of accidents with no spill & 204 & 91 & 22 & 15 & 27 & 49 \\
\hline Number of accidents with spill & 28 & 14 & 7 & 1 & 2 & 4 \\
\hline Total number of accidents & 232 & 105 & 29 & 16 & 29 & 53 \\
\hline Total quantity & 231199 & 221845 & 140 & 0 & 8851 & 36.3 \\
\hline Index (t/ship years) & 35.0 & 104.3 & 0.1 & 0.0 & 10.4 & 0.2 \\
\hline
\end{tabular}



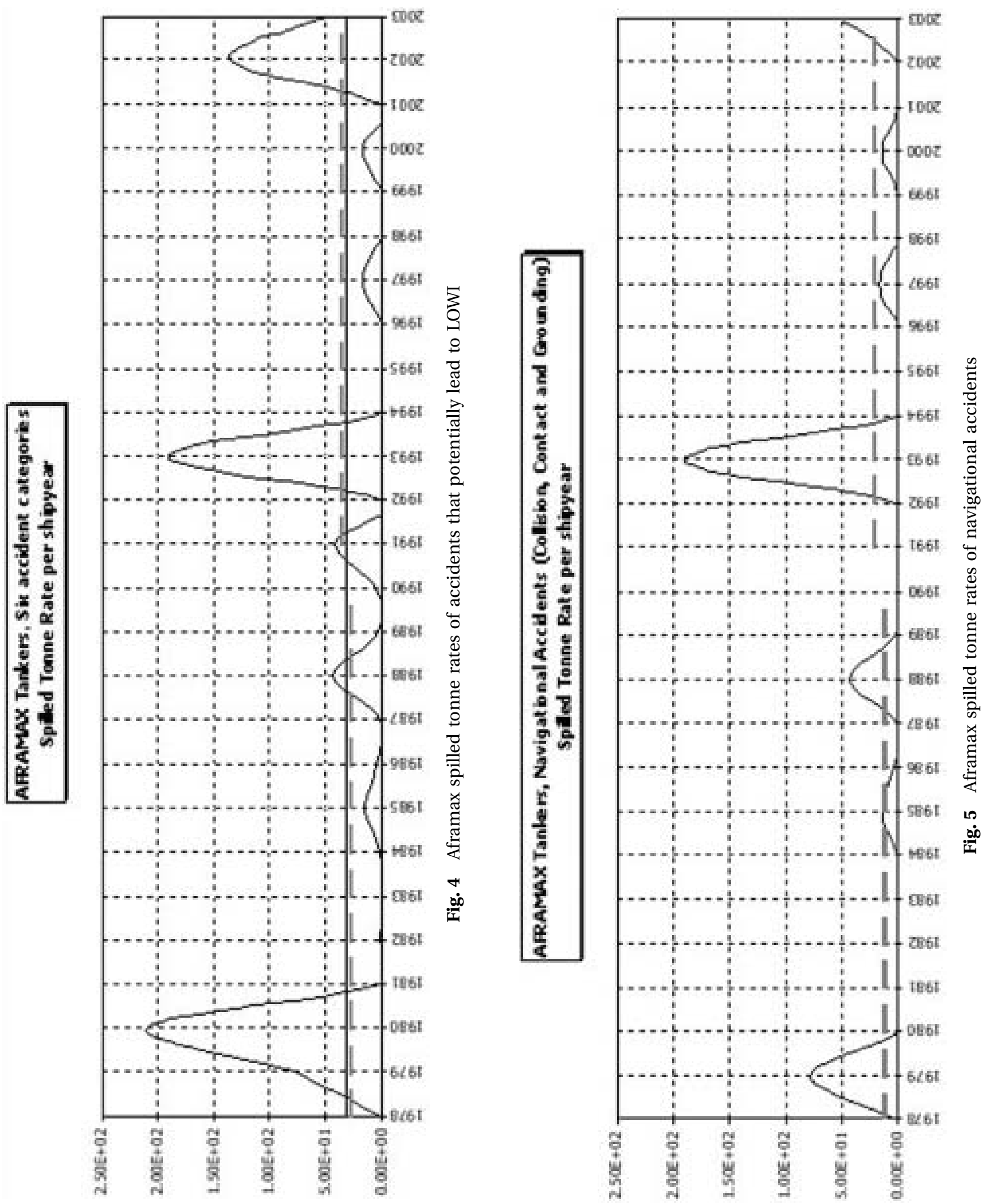


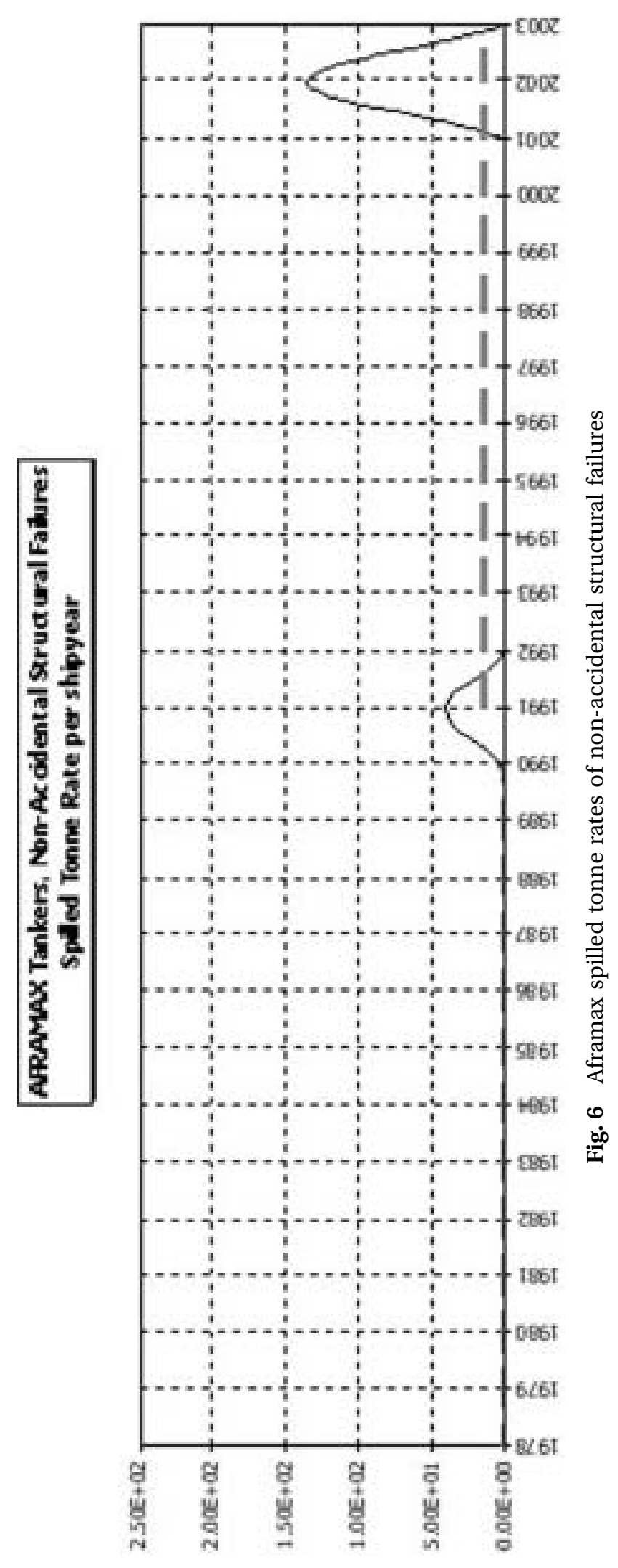

increases in the later period and this increase is made up from an improvement in the performance of the SH-SBT/PL tankers (which is comparable with the double-hull fleet) and from a deterioration in the performance of the SH-non-SBT/PL tankers, which in the second period has experienced accelerated ageing.

\subsection{Synoptic accident rates considering the ship's age}

Figure 7(a) presents the accident rates for all hull configurations by accident category and by age groups (of 5 year periods). Figure 7(b) presents the same information but this time for accidents with a serious degree of severity, including accidents which led to total losses of ships.

As far as the navigational accidents are concerned, namely collisions, contacts, and groundings, there is no clear and consistent trend between accident rates and age. On the other hand, non-accidental structural failures and, to a smaller extent, fires and explosions appear to be showing a 'bell-shaped' behaviour whereby there is higher frequency of accidents during the 'middle age' of the ships' lives.

Further studies at the Ship Design Laboratory, National Technical University of Athens, on Suezmax tankers [8] and on very large crude carries (VLCCs) and ultra-large crude carries (ULCCs) [9] appear to demonstrate similar trends.

\subsection{Non-accidental structural failures, accident rates by hull configuration and ship's age}

The reason for attempting to account for the effect of age on Aframax accidents was that, when results from this project were presented on the first comparisons of the pollution index of single- and doublehull tankers, showing a far superior performance of the double-hull configuration, repeated comments that such a comparison is inequitable because of the very much younger age distribution of the doublehull tanker fleet compared with the single-hull fleet were received. The section above, containing the synoptic results, would suggest that the primary area of emphasis in the analysis of the effect of age should be the non-accidental structural failures. In this section the focus is therefore on examining how age affects the historic rates of non-accidental structural failure for each type of hull configuration.

Figure 8 presents the non-accidental structural failure rates of the combined Aframax fleet (i.e. all hull configurations), by age, on an annual basis. Likewise, Fig. 9 compares the same information for 


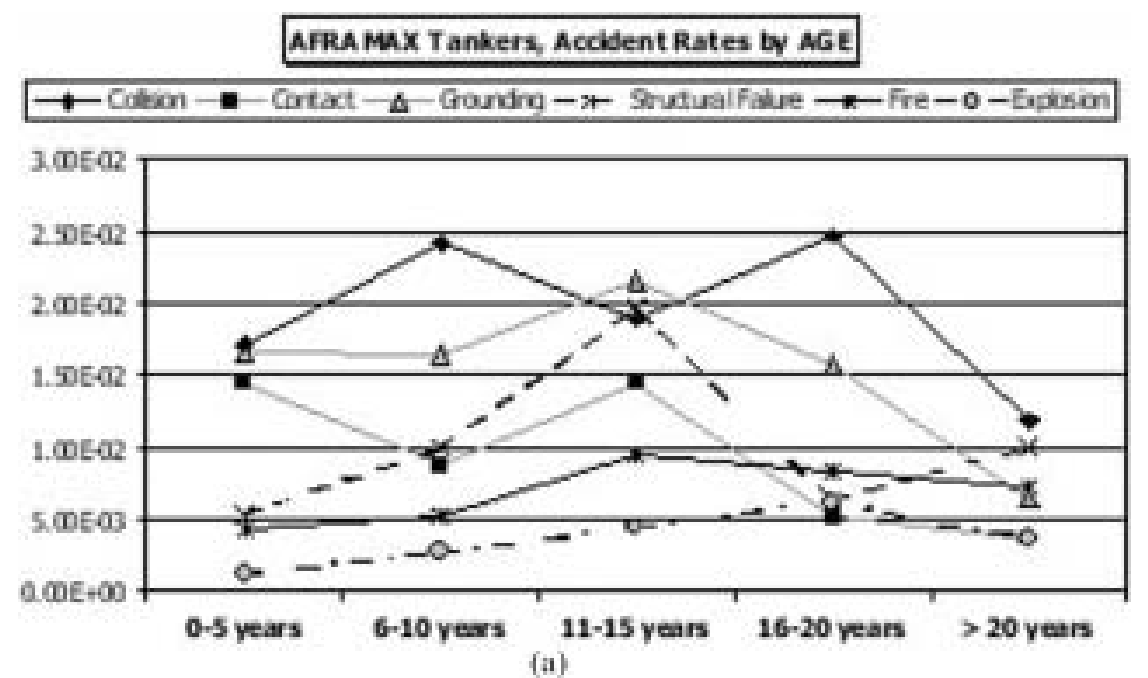

AFRAMAX Tankers, Rates of Acciderts

With serious consequences 8 total losses by AGE

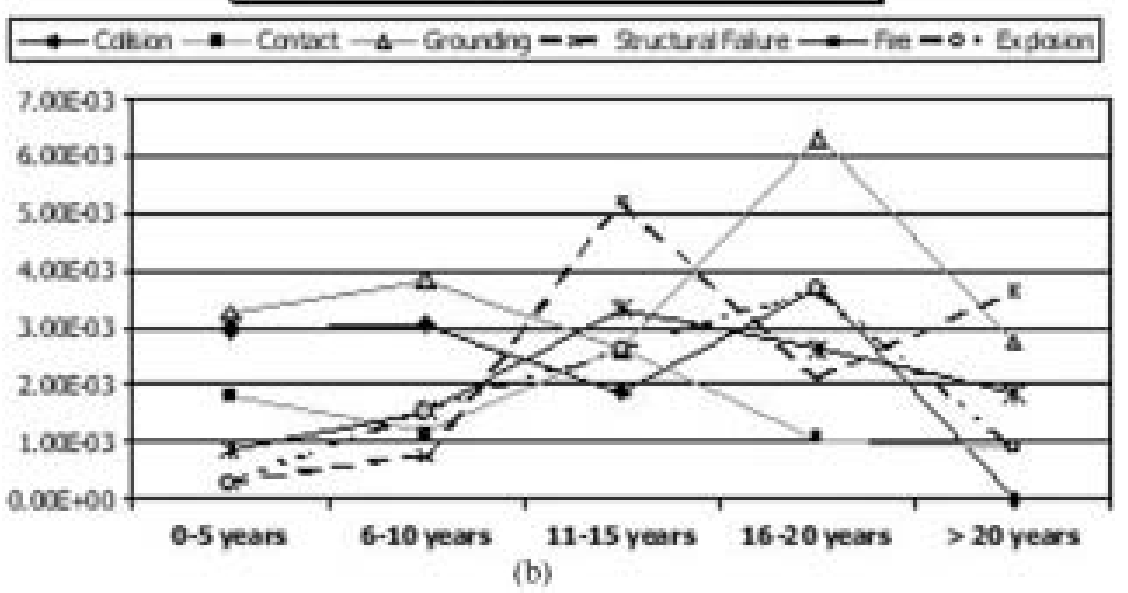

Fig. 7 (a) Rates of all accidents; (b) rates of accidents with serious and catastrophic consequences, by accident category and ship's age (groups of 5 year periods)

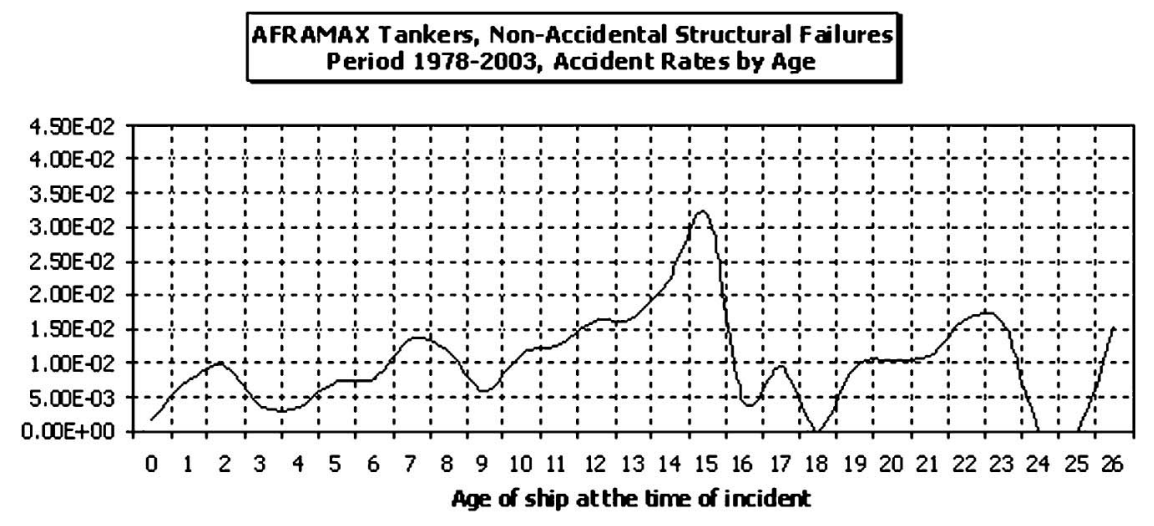

Fig. 8 Non-accidental structural failure rates of all ships

the SH-non-SBT/PL fleet and for the double-side fleet, while Fig. 10 compares the same information for the SH-SBT/PL and for the double-hull fleets. Because the double-bottom fleet is too small, its frequency distribution is erratic (lack of statistical significance) and as such it was avoided, producing a graph of the age distribution of the double-bottom fleet. 


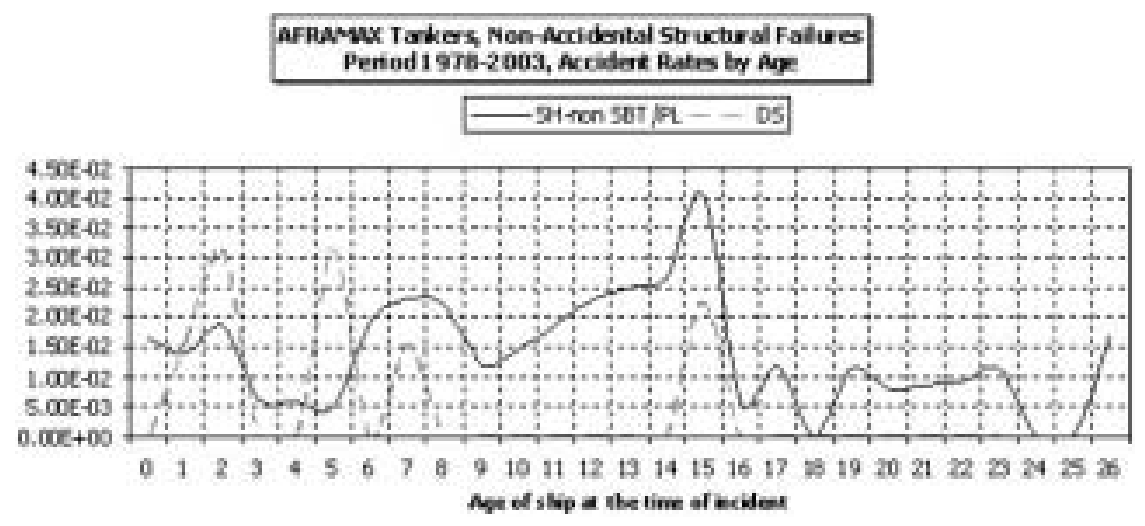

Fig. 9 Non-accidental structural failure rates of SH-non-SBT/PL and of double-side ships

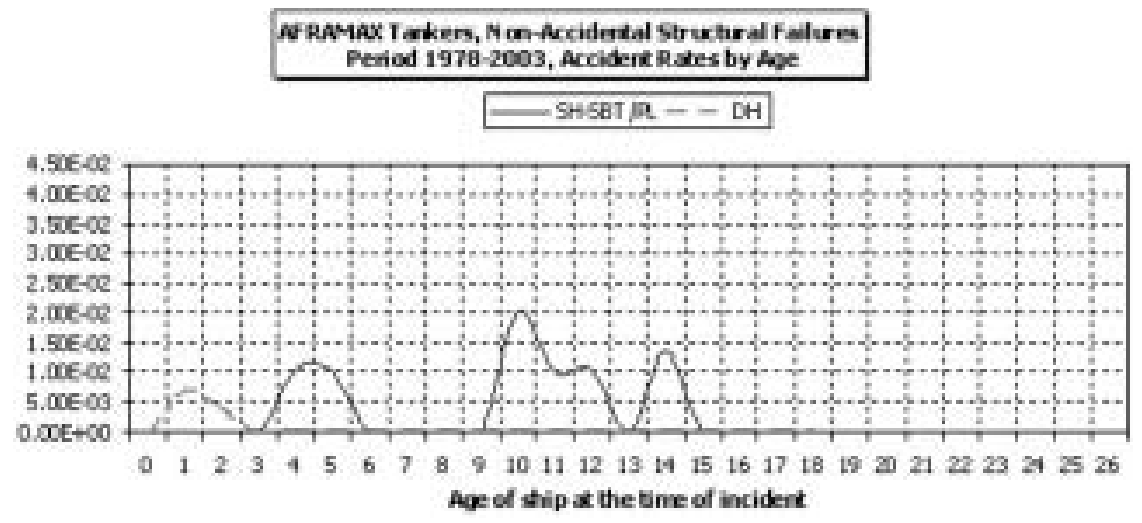

Fig. 10 Non-accidental structural failure rates SH-SBT/PL and of double-hull ships ships

The analysis contained in Figs 8 to 10 indicates the following.

1. SH-non SBT/PL ships (pre-MARPOL tankers) produced a particularly poor record.

2. SH-SBT/PL ships (MARPOL tankers) have a very much better record than their predecessors.

3. The fleet of the double-hull tankers is probably still too young to allow any firm conclusions to be made, although it could be said that the appearance of the two non-zero values at the ages of 1 and 2 years old could be a source of some concern.

Focusing on the non-accidental structural failures which occur to ships of age up to 5 years, it can be stated that double-hull ships have lower but non-negligible rates.

Considering non-accidental structural failures which occur to ships of age between 11 and 15 years, SH-non-SBT/PL ships presented by far the highest rates, while it is still too early to attempt to draw any conclusions on the performance of middle-aged double-hull tankers.

\subsection{Geography of oil spills caused by Aframax tankers}

Figure 11 shows the worldwide geographic locations (Marsden grid coding) of registered oil pollution caused by Aframax tankers over the studied period (1978-2003). Light-grey squares present a total pollution quantity of less than $7 \mathrm{t}$ over the studied period, grey squares present a total pollution quantity in the range of 7-700 $t$, and the black squares indicate a total quantity of greater than $700 \mathrm{t}$ of oil spilt.

The most severely affected areas worldwide by Aframax tankers, (over $700 \mathrm{t}$ oil spilt) are the east and centre Mediterranean, Scapa Flow, UK, Gulf of Mexico, Caribbean Sea, Pacific Coast of North America, Straits of Malacca, and Southwestern Australia. 


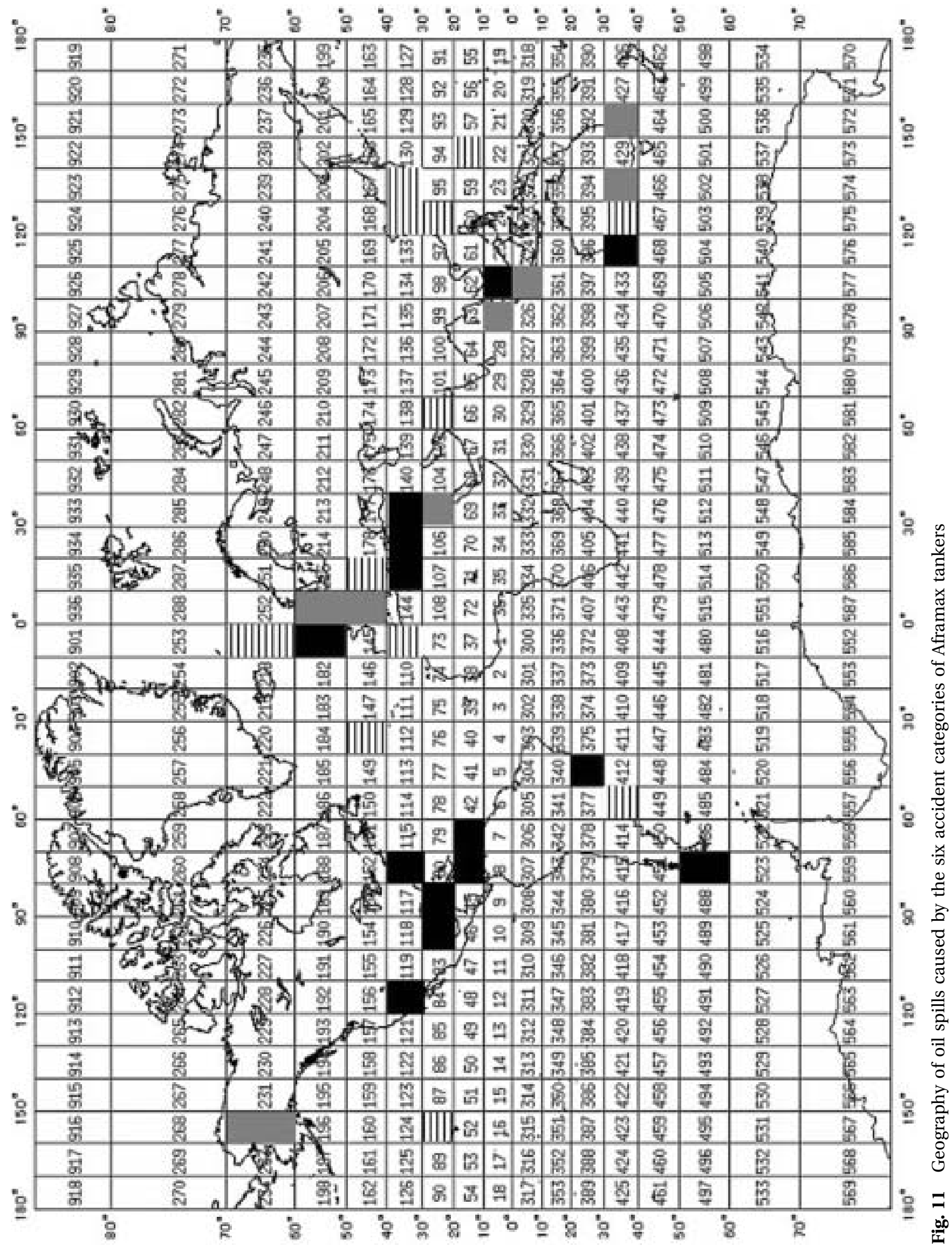




\section{CONCLUSIONS}

Accident databases such as that utilized by POP\&C are potentially important tools for gauging the safety and the environmental performance of the industry. They can be used to guide the regulatory process so that the regulations that are being produced may be focused so as to address the weakest links in the safety and environmental prevention chain, and also they can be used to provide alerts for areas of design, operation, and training which may be in need of additional attention or of a new approach.

Whereas the recognition of the potential value of marine accident databases is not new, the databases that currently exist suffer from two basic and serious weaknesses that greatly diminish the ability to utilize these data. These two problems were faced by the analysts of the POP\&C project and, although they could not be resolved within this project, the experience gained is certainly worthy of dissemination because, until these problems start being resolved, accident data will remain mostly underutilized.

It might be argued that many maritime accident records already exist in the public domain in the form of commercially available casualty databases (examples are the old LMIS database, the Lloyd's Register-Fairplay database, and the Lloyd's Marine Intelligence Unit database). Whereas these international databases contain a plethora of records of shipping casualties (and a plethora of records are certainly needed in order to arrive at statistically meaningful conclusions), they all tend to suffer greatly from the fact that the source of their information is, more often than not, non- technical, and anyone who has worked with such data will probably confirm this serious limitation.

The second stumbling block to the utilization of accident data arises from the way that the information is categorized. Accidents are assigned a single category, such as collision, grounding, fire-explosion, hull and machinery, etc. This onedimensional categorization ignores the basic fact that accidents are sequences of undesirable events, each of these having their own probability profile; e.g. a fire can lead to loss of power or steering, which in turn can lead to grounding. Using a single code to define an accident takes away vital information for any subsequent analysis and in the days of computers is an unnecessary restriction. It should therefore be evident that accident categorization (accident taxonomy) is in need of a rethink and a restructure.

The historical analysis of accidents presented in this paper was performed in order to populate the
POP\&C fault trees and event trees with the necessary frequencies and consequences data. The populated fault trees and event trees would then be used to conduct the risk assessment of the Aframax fleet. As discussed earlier, the POP\&C database was designed in a manner that helped the analysts to code, through drop-down menus and checklists, all the key information that could be extracted from the narrative of each record of an incident of accident. In effect the resultant codes, like stepping stones, aim to define the sequence of events in each accident. The events leading up to the accident are part of the fault tree and define the frequency (probability) of the accident, while the events after the accident belong to the event tree and define the consequences of the accident (consequence and its magnitude, on life, environment, and property).

For all Aframax tankers, the accident rate per ship year has reduced significantly when considering pre-1990 and post-1990 accidents (by a factor of about 3). However, the rate of accidents leading to pollution per ship year has reduced by a less significant amount (by around 35 per cent).

From the various tanker hull design concepts currently operating, it appears that the double-hull and the SH-SBT/PL perform best in all accident categories in terms of spilled tonne rates.

The correlation between a ship's age and the probability of suffering an accident is not straightforward; middle-aged ships appear to be more sensitive to non-accidental structural failures, compared with older and younger ships. This is clearly so with single-hull ships and remains to be clarified for the double-hull ships, currently too young in age to be conclusively assessed.

The analysis of geographical locations of recorded accidents with high pollution showed that the east Mediterranean, Gulf of Mexico, and Caribbean Sea were the most heavily polluted areas by Aframax oil tanker accidents in the period 1978-2003.

\section{ACKNOWLEDGEMENTS}

A major part of the particular study presented herein was financially supported by the European Commission under the Growth Programme of the Sixth Framework Programme. Support was given under the Specific Targeted Research Project scheme, Contract FP6-PLT-506193.

The European Community and the authors shall not in any way be liable or responsible for the use of any such knowledge, information, or data, or of the consequences thereof. 


\section{REFERENCES}

1 International Maritime Organization, Amendments to the Annex of the Protocol of 1978 relating to the International Convention for the Prevention of Pollution from ships, 1973 (Amendments to Regulation 13G, Addition of New Regulation 13H and Consequential Amendments to the IOPP Certificate of Annex I of MARPOL 73/78). Resolution MEPC.111(50), Marine Environment Protection Committee, adopted 4 December 2003.

2 Papanikolaou, A., Eliopoulou, E., Alissafaki, A., Aksu, S., Tuzcu, C., Delautre, S., and Mikelis, N. Critical review of Aframax tankers incidents. In Proceedings of the Third International Conference on Marine Science and Technology for Environmental Sustainability (ENSUS 2005), Newcastle upon Tyne, UK, April 2005.

3 International Maritime Organization, Reports on marine casualties and incidents. MSC/Circular 953, Maritime Safety Committee, 14 December 2000.

4 Papanikolaou, A., Eliopoulou, E., Mikelis, N., Aksu, S., and Delautre, S. Casualty analysis of tankers. In Proceedings of the Third Conference on Learning from Marine Incidents, London, UK,
January 2006 (Royal Institution of Naval Architects, London).

5 Mikelis, N., Delautre, S., and Eliopoulou, E. Tanker safety record at all-time high. Lloyd's List, 29 September 2005.

6 Papanikolaou, A., Eliopoulou, E., Alissafaki, A., Aksu, S., Delautre, S., and Mikelis N. Systematic analysis and review of Aframax tankers incidents. In Proceedings of the 11th International Congress of the International Maritime Association of the Meditteranean (IMAM 05), Lisbon, Portugal, September 2005.

7 Papanikolaou, A., Eliopoulou, E., and Mikelis, N. Impact of hull design on tanker pollution. In Proceedings of the 9th International Marine Design Conference (IMDC), Ann Arbor, Michigan, USA, May 2006.

8 Kanellakis, G. Casualty analysis of Suezmax tankers. Diploma Thesis, Report in Greek, Ship Design Laboratory, National Technical University of Athens, 2005.

9 Bourikas, E. Casualty analysis of VLCC and ULCC tankers. Diploma Thesis, Report in Greek, Ship Design Laboratory, National Technical University of Athens, 2005-2006. 


\section{APPENDIX}
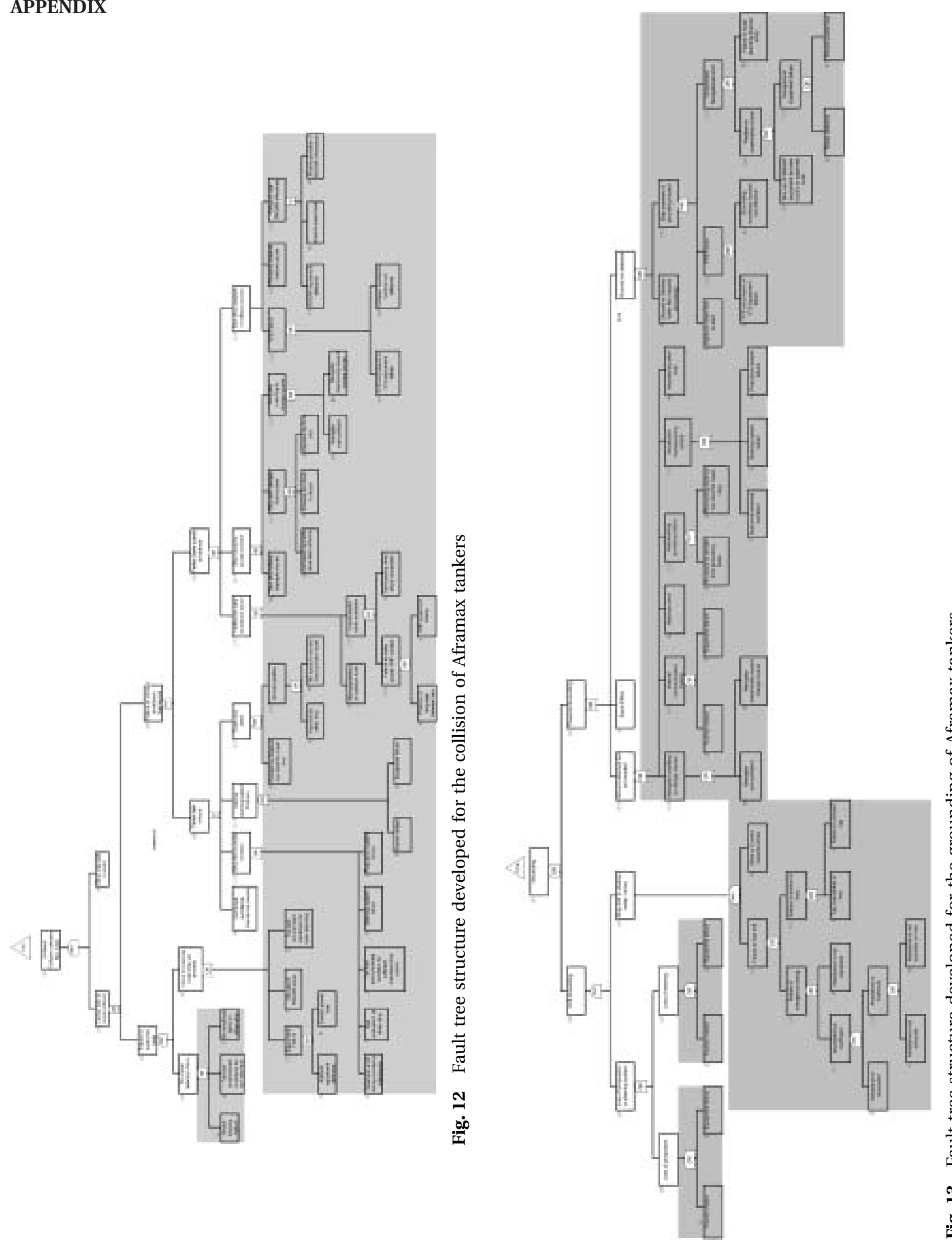

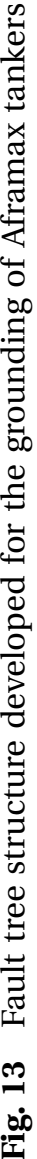



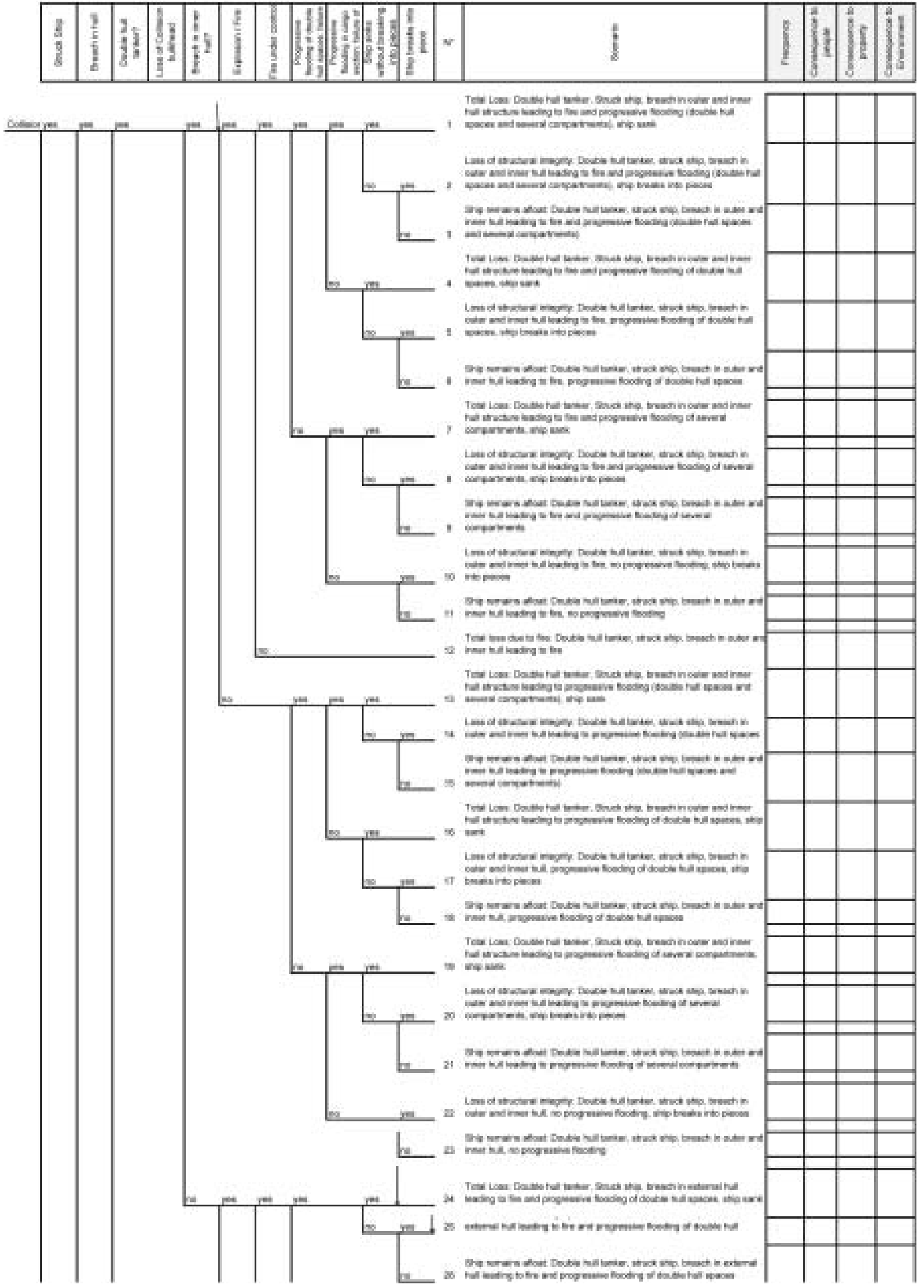

Fig. 14 Event tree structure developed for the collision of Aframax tankers 


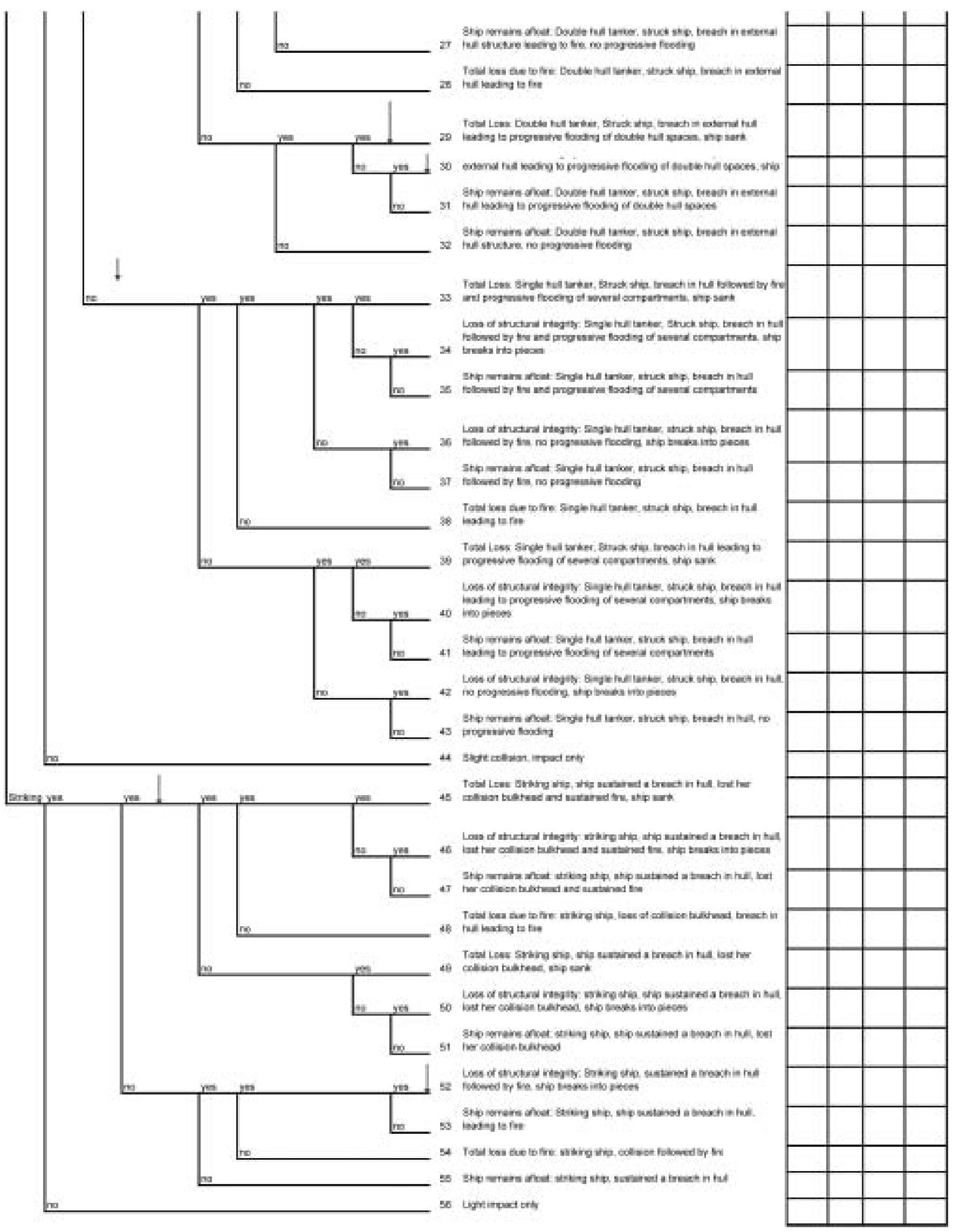

Fig. 14 (Continued) 


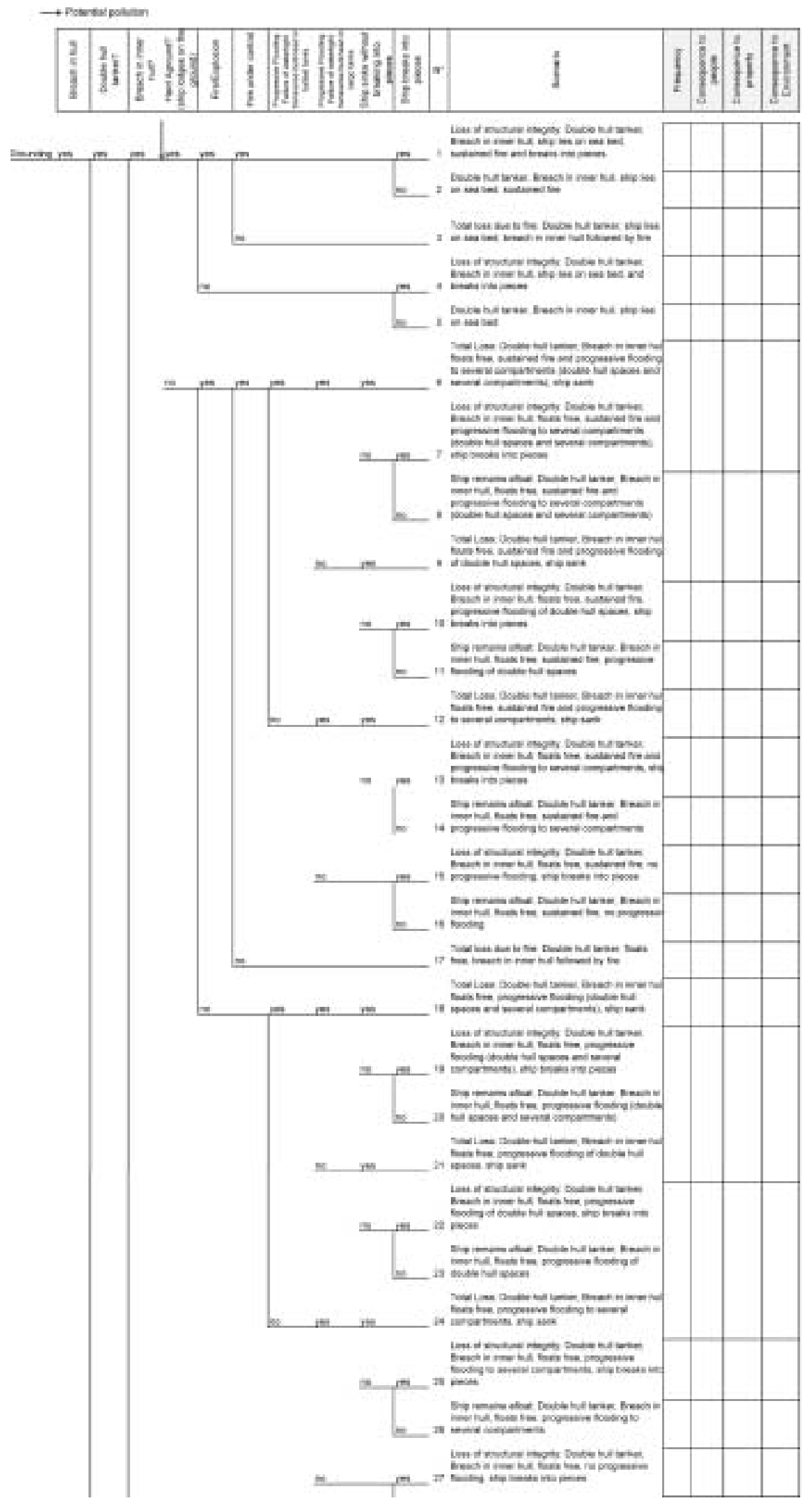

Fig. 15 Event tree structure developed for the grounding of Aframax tankers 


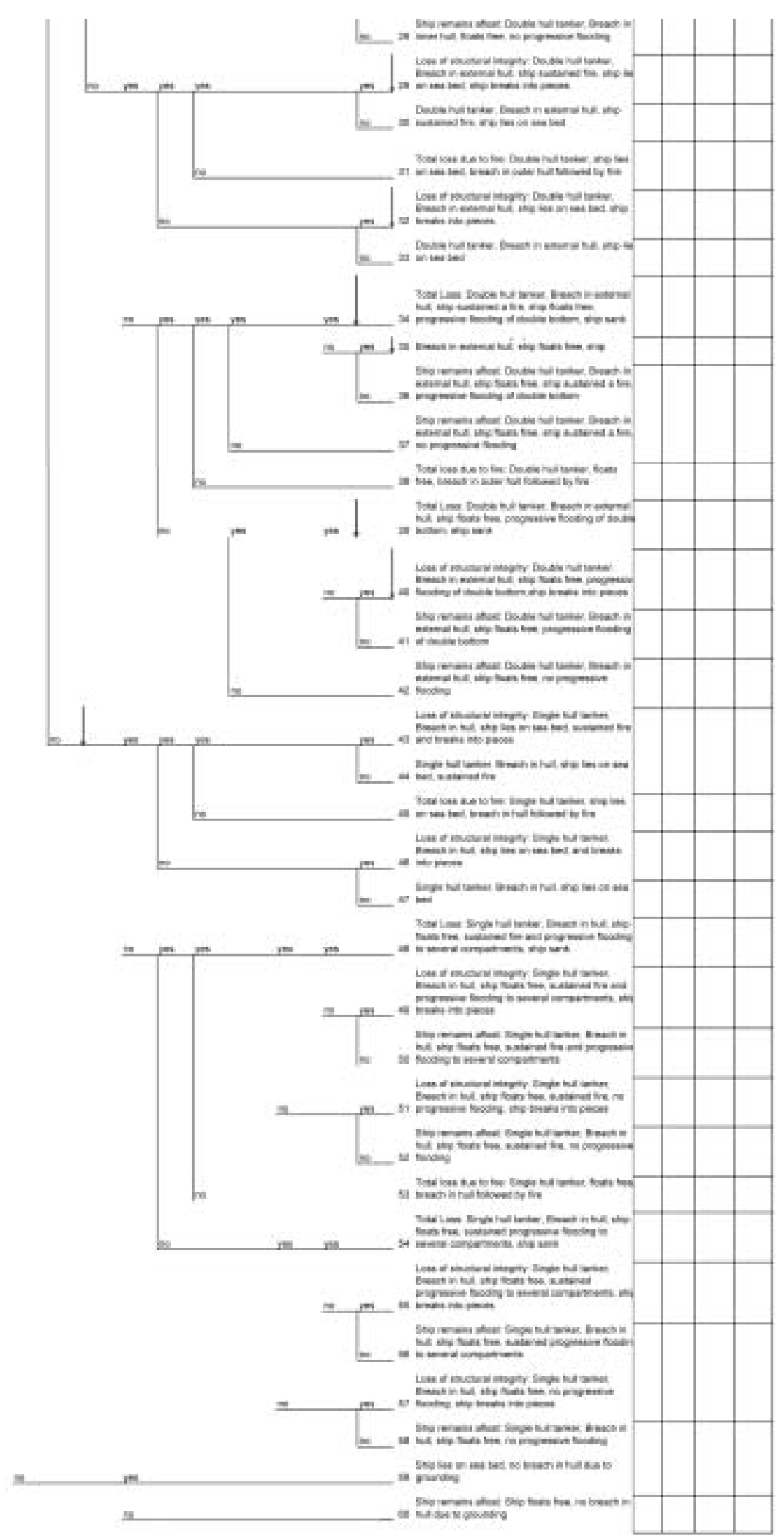

Fig. 15 (Continued) 